\title{
МЕТОДЫ ДЕНДРОИНДИКАЦИИ ЭКЗОГЕННЫХ ГРАВИТАЦИОННЫХ ПРОЦЕССОВ: ОБЗОР
}

\author{
(C) 2020 г. С. А. Николаева ${ }^{a,}$ *, Д. А. Савчук ${ }^{a, ~ * *}$ \\ ${ }^{a}$ Институт мониторинга климатических и экологических систем СО РАН, Томск, Россия \\ *e-mail: sanikol1@rambler.ru \\ **e-mail: savchuk@imces.ru \\ Поступила в редакцию 26.05.2019 г. \\ После доработки 09.07.2019 г. \\ Принята к публикации 30.01.2020 г.
}

\begin{abstract}
С начала XXI в. дендроиндикационные исследования экзогенных гравитационных процессов (ЭГП) в Западной Европе резко активизировались, а в России, наоборот, значительно сократились. В современной зарубежной литературе по этой тематике разрабатываются новые подходы и методы исследования обусловленных ЭГП явлений на склоне, различные аспекты которых продолжают обсуждаться. Дан краткий обзор дендроиндикационных методов выявления, датирования и реконструкции обусловленных ЭГП явлений в прошлом (сели, лавины, обвалы/камнепады) на разных этапах дендрогеоморфологического исследования. Эти исследования основаны на концепции Дж. Шродера: “процесс-событие-отклик". Как результат, выполнялись пространственно-временные реконструкции склоновых явлений на конкретных участках, т.е. оценка протяженности, частоты явлений и интенсивности процесса. Рассматриваются преимущества и ограничения методов, слабо разработанные или нерешенные проблемы дендроиндикации.
\end{abstract}

Ключевые слова: дендрогеоморфология, сель, лавина, обвал, камнепад, годичные кольца, травмы, радиальный прирост

DOI: $10.31857 / \mathrm{S} 2587556620030097$

\section{ВВЕДЕНИЕ}

Один из основных вопросов экологии - связь растительности и среды. Свойства среды по реакции растительности оценивают методами фитоиндикации. Одним из ее направлений является фитоиндикация рельефообразования, где растительность выступает как индикатор проявления факторов изменения рельефа [2]. Для оценки этих пространственно-временных проявлений используются разнообразные прямые и косвенные методы. При отсутствии или нерегулярности прямых наблюдений за экзогенными гравитационными процессами, происходящими на склонах, наиболее перспективными оказались косвенные дендроиндикационные (термин, используемый в отечественной литературе), или дендрогеоморфологические (термин зарубежной литературы) методы исследования $[2,7,21,30]$. Под экзогенными гравитационными процессами (ЭГП) мы понимаем массовое перемещение материала вниз по склону под действием силы тяжести. Обусловленные ими явления, происходящие на склоне (сели, лавины и обвалы/камнепады), будут рассмотрены в этой статье с точки зрения дендроиндикации. При всех их геоморфологических раз- личиях нам важно подчеркнуть общее свойство этих явлений с точки зрения деревьев как их главных индикаторов: перемещаемый со склона с высокой скоростью материал немонолитного характера и его ударное воздействие на деревья и/или изменение окружающей дерево среды. Последнее (ударное воздействие и/или изменение среды) вызывает у деревьев однотипные реакции [30], с помощью которых методами дендроиндикации как раз и можно выявить эти склоновые явления, произошедшие в прошлом, точно их датировать и пространственно реконструировать. Количество публикаций на тему дендроиндикации селей, лавин и обвалов/камнепадов, начиная с XXI в., в мире резко возросло. Большая часть таких исследований сосредоточена в Альпах [см., например, 11, 13, 31]. В России большинство дендроиндикационных публикаций относилось к 1970-1990-м годам, а в последние два десятилетия их количество резко сократилось. В настоящее время в современной зарубежной дендрогеоморфологической литературе разрабатываются новые подходы, обсуждаются различные аспекты дендроиндикационных методов [см. обзоры 7-9, 17, 25, 27, 30-34 и др.]. Цель статьи - дать краткий обзор дендроиндикационных методов выявления, датирования и ре- 
Таблица 1. Схема концепции “процесс-событие-отклик” по Дж. Шродеру [22] с дополнениями [7, 27, 29] и нашими уточнениями

\begin{tabular}{|c|c|c|}
\hline Процесс (process) & Событие (event) & Отклик (response) \\
\hline $\begin{array}{l}\text { - Сель } \\
\text { • Лавина } \\
\text { - Обвал } \\
\text { - Камнепад } \\
\text { • Оползень } \\
\\
\text { и т.п. }\end{array}$ & $\begin{array}{l}\text { - Механическое нарушение целостности } \\
\text { особи: } \\
\text { - травма на стволе, ветвях и корнях } \\
\text { - декапитация (слом ствола от верхушки } \\
\text { до основания, облом ветвей) с появлением } \\
\text { ветвей замещения } \\
\text { - Изменение формы роста: } \\
\text { - наклон/изгиб основания ствола } \\
\text { - Изменение условий роста особи при: } \\
\text { - погребении основания ствола } \\
\text { - обнажении корней } \\
\text { - снижении конкуренции }\end{array}$ & $\begin{array}{l}\text { • Каллюсная ткань } \\
\text { • Тангенциальные ряды травматиче- } \\
\text { ских смоляных ходов } \\
\text { • Реакционная древесина, или древе- } \\
\text { сина сжатия/расширения } \\
\text { • Резкое и продолжительное измене- } \\
\text { ние прироста (снижение/увеличение) } \\
\text { • Эксцентричность роста ствола }\end{array}$ \\
\hline
\end{tabular}

конструкции обусловленных ЭГП явлений в прошлом (сели, лавины, обвалы/камнепады) на разных этапах дендрогеоморфологического исследования. Индикаторами выступали деревья чаще хвойных видов, а основными маркерами их реакций - изменения в структуре и размерах годичных колец, а также возраст деревьев. При этом акцент сделан на последовательном (“от задачи до результата”) описании таких методов, выявлении их преимуществ и ограничений, определении нерешенных дендроиндикационных проблем. Сравнение разных дендроиндикационных методов между собой не предполагалось, так как задача состояла не выбрать из них лучший, а применять их в комплексе, взаимно дополняя друг друга во имя наиболее полного выявления склоновых явлений в конкретной горной местности во времени и в пространстве.

I. Теоретические предпосылки и методы. Дендроиндикационные исследования основаны на концепции “процесс-событие-отклик", предложенной Дж. Шродером [22], элементы которой были систематизированы в дальнейшем [7, 25, 28, 29]. Главным элементом в этой концепции выступает дерево. "Процесс" представляет собой любое склоновое явление как внешний фактор, воздействующий на дерево (табл. 1, первая колонка). Под "событием" понимается тип внешнего повреждения дерева (разные механические нарушения целостности особей) или изменения среды для дерева, вызванные склоновым явлением (см. табл. 1, вторая колонка). Эти признаки можно назвать внешними индикаторами воздействия. “Отклик", или нарушения роста (growth disturbance) дерева - это ростовые реакции (внутренние индикаторы), связанные с "событием" (см. табл. 1, третья колонка). Он проявляется в нарушении анатомической структуры и/или изменении ширины годичных колец: образовании каллюсной ткани и травматических смоляных ходов после травмы ствола, резком снижении прироста при погребении основания ствола и декапитации, увеличении прироста после гибели соседних деревьев, эксцентричности роста и образовании реакционной древесины при наклоне/изгибе ствола.

Дендроиндикационный подход (выявление, датирование и пространственная реконструкция склоновых явлений по дендроиндикационным признакам у деревьев) включает в себя (1) выбор модельных участков с ЭГП, (2) отбор модельных деревьев и образцов на них, (3) анализ реакций и силы отклика деревьев на эти процессы, (4) пространственно-временную реконструкцию склоновых явлений. Тематическое исследование разбивается на несколько этапов, каждый из которых включает свои нижеизложенные подходы и методы, которые позволяют выявить влияние геоморфологических факторов и минимизировать воздействие климатических и других факторов. На подготовительном этапе привлекались недендроиндикационные методы, на последующих использовались дендроиндикационные. Последние классифицированы А.М. Лехатиновым [3]. В таких работах исследователи применяли различные сочетания методов и дендроиндикаторов в зависимости от характера ЭГП, древесного вида и др. [см. обзоры 1, 7, 23, 27, 30, 31, 33].

II. На подготовительном этапе дендроиндикационного исследования привлекалась любая информация, способствующая подбору модельных участков с ЭГП и уточнению пространственновременных характеристик последних [1, 7, 27]. Этот этап включает: (1) анализ изображений выбранной территории за разные годы, особенностей ЭГП, а также факторов, способствующих их активизации (наличие обломочного материала, параметры климата и т.п.); (2) анализ характеристик растительности и ее распределения по территории; (3) сбор свидетельств о явлениях на склоне; (4) выбор модельных (ключевых) участ- 
ков; (5) сбор и анализ дополнительной информации для них.

Идентификация признаков ЭГП на территории начиналась с изучения и интерпретации ее изображений: карты-схемы, аэрофотоснимки, спутниковые изображения, изображения с беспилотных летательных аппаратов. Подбор изображений одной и той же территории за разные годы позволял выявлять новые следы от прошедших ЭГП и изменения в растительности. Детальная геоморфологическая карта служила основой для выбора и точного позиционирования деревьев [7, $12,15,27,30]$. Сведения о погодно-климатической изменчивости использовались при выявлении причин и датировании разных типов склоновых явлений, особенно на участках смешанного генезиса (см., например, [24]).

Изменения состава и структуры растительности позволяли качественно оценивать частоту и/или мощность процессов, а с помощью древесной растительности - точно датировать явления [1, 27].

Непосредственные наблюдения (литературные источники, сеть Интернет, опрос очевидцев, собственные наблюдения, архивные данные) нередко привлекались как независимый источник информации о склоновых явлениях и для оценки полноты дендроиндикационного датирования [34]. За рубежом большинство таких исследований выполнялись на участках, для которых собраны многолетние (иногда многовековые) свидетельства о склоновых явлениях. В России наибольшее количество таких свидетельств имеется для горных территорий Кавказа и Прибайкалья. Анализ тематической литературы [11, 13, 20, 34] показал, что ряды непосредственных наблюдений даже в районах, где налажен постоянный мониторинг ЭГП, обычно являлись неполными. При этом явления, в частности, лавины, зарегистрированные в архивах, датировались дендроиндикационными методами только в 40-50\% случаев. Это связано с особенностями конкретных участков, характером древесной растительности, интенсивностью процесса, а также наличием на участке наблюдателей и особенностями человеческой памяти.

При выборе модельных (ключевых) участков, особенно на новых территориях, рекомендовалось отдавать предпочтение таким, на которых преобладает один тип ЭГП. При этом желательно наличие сведений о прошедших на них склоновых явлениях [1, 7].

В дендроиндикационных исследованиях для идентификации и оценки ЭГП полезной являлась дополнительная информация: состав и структура растительности (фитоценотическая индикация), характеристика слоев селевых отложений (седиментационно-стратиграфическая индикация), возраст ископаемой древесины (радиоуглерод- ный анализ) и т.п. [1, 23]. Эта информация вместе с геолого-геоморфологическими сведениями о территории позволит полнее выявить на ней склоновые явления прошлого.

III. Полевые исследования включают (1) идентификацию прошлой склоновой активности на местности, (2) отбор и картирование нарушенных внешними воздействиями и ненарушенных (контроль) деревьев на конкретных участках склона, (3) учет различных типов нарушений у деревьев, (4) выбор вида древесного образца и высоту его отбора на стволе дерева, (5) определение объема выборок деревьев, необходимых для исследования.

Прошлые ЭГП и их геоморфологические признаки, выявленные по изображениям территории, идентифицировались на местности для отделения их от следов других типов ЭГП и антропогенных воздействий, чтобы избежать неправильной интерпретации результатов [27].

Выбор модельных деревьев и древостоев при дендроиндикационных исследованиях производился иначе, чем при дендроклиматических, изза различных лимитирующих факторов, действующих на дерево - главный индикатор ЭГП [5], хотя погода и климат играют значительную роль в активизации ЭГП. Отбор деревьев на местности зависит от типа ЭГП и наличия повреждений у них. В дендроиндикации использовались четыре способа такого отбора: целенаправленный, по трансектам, метод сетки и случайный [9]. При исследовании селей и лавин преимущественно применяли первый способ отбора, обвалов/камнепадов - по трансектам [31].

Выбор контроля, в качестве которого чаще всего выступает древостой, где воздействие ЭГП минимально, часто являлся очень трудным [5]. В качестве контрольных использовали ряды прироста, полученные с нетравмированных деревьев, растущих (1) на соседних ненарушенных участках склона [17, 24, 25, 27, 34] или (2) на тех же участках, где изучался ЭГП [15]. Во втором случае контролем могли выступать и травмированные деревья, у которых (3) ряды прироста получены с неповрежденных секторов ствола [12], или (4) взят отрезок ряда, соответствующий времени их жизни, когда влияние ЭГП отсутствовало [5]. Встречались и комбинации вышеуказанных способов.

Все модельные деревья фиксировались на спутниковых изображениях, фотографировались, записывалась информация о них (высота, диаметр, характер повреждений, качество керна, наличие соседних деревьев и т.п.). В случае, когда на изучаемых участках полог деревьев достаточно плотный, рекомендовалось проводить обычное картирование деревьев [27].

Для выявления и датирования явлений учитывались различные типы внешних и внутренних нарушений деревьев (см. табл. 1), которые пред- 
ставляют собой механические повреждения и нарушения целостности деревьев и/или ростовые реакции их различных частей $[7,28]$.

Для анализа ростовых реакций использовались три вида древесных образцов: спил, выпил (клин) и керн. На спиле фиксируется вся доступная информация, но взятие такого образца является летальным для дерева. В случае керна велика вероятность потери части необходимой информации, но взятие таких образцов наименее травматично для дерева. При современных дендроиндикационных исследованиях, как правило, с живых деревьев брались керны, с погибших - спилы/выпилы. Образцы обычно отбирались на высоте видимых повреждений или в пределах изогнутого сегмента ствола $[25,27,29,31]$.

Стандартная величина минимального размера выборки, необходимая для датирования явлений, в литературе отсутствует, поскольку ее размер возрастает при увеличении площади и сложности строения участков склона с ЭГП, типа ЭГП, а также зависит от личного выбора исследователя. Ее рекомендуемый размер у разных авторов сильно варьирует: от 20 до 100 деревьев [9, 11]. Общее эмпирическое правило: “чем больше, тем лучше". В тематических исследованиях минимальный размер выборки - 6-35 деревьев. Но реконструированная по ним частота событий считалась неполной, а пространственная реконструкция фрагментарной. Максимальные размеры выборок составляли несколько сотен и даже тысячу деревьев при работе на крупных и сложных по строению участках склона. Но такие исследования являлись длительными по времени и не экономичными по затратам $[8,9,13,28,31,33]$. Поэтому при определении размера выборки рекомендовалось сбалансировать продолжительность исследования, полевую логистику, требования техники безопасности и финансовые затраты [8].

Количество контрольных деревьев обычно составляло от 15 до 30. Для построения обобщенной (локальной) древесно-кольцевой хронологии в зависимости от возрастного строения древостоев отбирались деревья как близкого, так и разного возраста, либо сведения о возрасте отсутствовали $[5,15,29]$.

IV. Лабораторные исследования включают (1) подготовку и измерение собранных древесных образцов, (2) перекрестное датирование древесно-кольцевых серий, (3) определение времени воздействия склонового явления с помощью различных видов дендроиндикаций и конкретных индикаторов, (4) определение интенсивности реакции деревьев. На основе этого оценивается (5) интенсивность склоновых явлений.

Методы подготовки, измерения древесных образцов и их перекрестной датировки являются стандартными. При перекрестной датировке срав- нивались индивидуальные ряды ширины годичных колец и находилось соответствие в характере их изменчивости. Все эти процедуры подробно описаны в литературе [5].

При ретроспективном датировании явлений использовался ряд методов дендроиндикации, основанных на изменении размера и структуры годичных колец древесины, а также возраста деревьев, с соответствующими индикаторами, или маркерами [2, 3, 27, 30].

Травматическая дендроиндикация - определение времени нанесения механического повреждения дереву. Маркеры: (1) травма (рана) преимущественно ствола, обычно сопровождаемая образованием (2) каллюсной ткани (см. табл. 1), которая разрастается от краев раневой поверхности ствола дерева, защищает место ранения, накапливает питательные вещества и способствует заживлению раны. Травматическая дендроиндикация хорошо проиллюстрирована, например, в [7]. Считается [27], что для точного датирования травм на стволе дерева наилучшим направлением взятия керна (если нет возможности взять спил) будет сектор ствола недалеко от травмы, где одновременно имеются в наличии каллюсная ткань и тангенциальные ряды травматических смоляных ходов. При правильном отборе деревьев это наиболее надежные индикаторы прошлой геоморфологической активности. Из анализа рекомендовалось исключать удлиненные ( $>2$ м) и очень маленькие $\left(<20 \mathrm{~cm}^{2}\right)$ травмы, а также травмы у небольших деревьев (диаметр $<5$ см) [30].

К этому же виду индикации условно можно отнести и определение года гибели дерева. Маркеры: (1) стоящий сухой или лежащий ствол, (2) пень. Год роста последнего наблюдаемого годичного кольца определялся после перекрестной датировки изучаемых образцов с контролем [30].

Точность датирования травм обычно составляет $\pm 1-2$ г., но она падает в случае потери периферических годичных колец при механическом сдирании древесины или при ее отслаивании после высыхания или гниении.

Дендрометрическая индикация - определение времени воздействия склоновых явлений по изменениям абсолютных или относительных величин радиального прироста. Существуют два подхода в рамках этой дендроиндикации. В первом случае маркер: резкое, значительное и относительно продолжительное изменение (снижение или повышение) прироста дерева. Индивидуальные ряды абсолютных или нормированных величин прироста по каждому нарушенному дереву сравнивались с локальной (контроль) хронологией. Способы анализа таких изменений роста, проводимые по каждому древесному образцу отдельно, еще не унифицированы. Такие кривые роста анализировались (1) визуально по индексам 
прироста травмированных и контрольных деревьев [27] или по качественным критериям оценки [11] либо (2) по количественным показателям интенсивности отклика дерева с учетом категорий $[14,16]$. Итоговые результаты представлялись в виде погодичных графиков/таблиц динамики количества деревьев с изменениями прироста. Исследования показали, что такое повышение прироста может идти с некоторым запаздыванием, поэтому оно являлось дополнительным маркером к другим типам индикаторов прошлых ЭГП $[13,30]$.

Во втором случае маркером являлось резкое, значительное, но не обязательно продолжительное снижение прироста дерева. Индекс прироста разработан для датирования селей и вычислялся как частное отношений величин ширины соседних колец травмированных и контрольных деревьев. Результат представлялся в виде графиков динамики нормированного прироста. Условием использования этого индекса являлся близкий возраст травмированных и контрольных деревьев [4].

У построенных для целей дендрометрической индикации хронологий радиального прироста есть естественный ограничитель их длительности, связанный с продолжительностью жизни деревьев. Преодолеть это ограничение можно, применяя датирование годичных колец полуископаемой древесины из погребенных давними селями горизонтов на селевых конусах.

Деформационная дендроиндикация - определение времени начала эксцентричного роста ствола дерева при наклоне и/или изгибе его основания. Эксцентричность роста является косвенным индикатором оползней, сползания снега, для оценки которых предложено несколько формул. Исследования показали, что появление эксцентричных колец после оползня может запаздывать на несколько лет, т.е. оно имеет слабые связи с этими событиями [33]. Стратегия преобразования рядов прироста на примере оползней показана в [17]. Деформационный метод предложено использовать для датирования селей и лавин [1, 34], что требует дополнительной проверки.

Анатомическая дендроиндикация - определение времени появления изменений в анатомической структуре древесины. Маркеры: (1) травматические (термин, используемый в зарубежной литературе), или патологические (в отечественной литературе), смоляные ходы и (2) реакционная древесина, или древесина расширения/сжатия (см. табл. 1). Этот метод хорошо проиллюстрирован в [26]. Метод успешно использовался для разграничения склоновых явлений на конусах смешанного генезиса в районах с муссонным климатом, где лавины сходят в начале сезона вегетации, а сели - в конце [24]. При своей высокой точности (сезон, месяц) этот метод трудоемкий и затратный по времени [31].

Установлено, что травматические смоляные ходы появлялись в течение трех недель после удара в древесине хвойных р. Larix, Picea, Abies, но не образовывались у деревьев р. Pinus [7, 27, 30]. В ряде работ [21, 33] отмечалось, что такие отклики дерева могли проявляться с задержкой по времени и различаться у разных видов деревьев.

Реакционная древесина имеет иные, чем в обычных кольцах, форму и строение клеток и образуется после наклона/изгиба ствола. Для индикации чаще использовалась древесина сжатия хвойных, которая визуально определяется по более темному цвету кольца. Реакционная древесина и эксцентричность роста имеют общую причину образования - наклон ствола [30, 33].

Возрастная дендроиндикация - определение времени появления основных генераций деревьев. Если склоновое явление было достаточно сильным, чтобы уничтожить деревья, то его оценка проводилась по возрасту появившихся генераций, как маркеру. Этот метод дает приблизительную оценку даты события: от 1 до 100 лет [1, 27, 30, 33]. Неопределенность датирования таким методом связана с (1) трудностями в определении точного возраста дерева по годичным кольцам, которая с повышением возраста только увеличивается, и (2) видоспецифичностью и локальностью времени заселения деревьями участка территории после разрушительного склонового явления.

Первая неопределенность связана с подсчетом колец для определения максимально близкого к реальному возраста дерева. Возраст вычислялся суммированием количества колец на (1) образце древесины, (2) отрезке керна от центра отсутствующей сердцевины до первого околосердцевинного кольца, (3) высоте взятия керна от “шейки корня” [6]. Для определения количества годичных колец вследствие неточного прохождения бурава через центр ствола дерева можно интерполировать размер годичного прироста путем усреднения размеров трех самых старых (околосердцевинных) колец, найденных на керне [16]. Если извлеченный из дерева керн имел стволовую гниль, то в зависимости от ее размера такие керны либо не учитывали, либо увеличивали величину поправки на возраст с учетом особенностей роста деревьев близкого возраста и фитоценотического положения. Прибавка на высоту взятия образца основана на допущении, что скорость роста деревьев в молодом возрасте (в толщину и до 0.5-1 м в высоту) линейна и одинакова у всех деревьев данного вида на этом участке [16]. Другой способ расчета: высоту дерева делили на количество годичных колец (лет) для получения средней скорости годичного линейного прироста для каждого дерева. Высота 
взятия образца потом делилась на величину этого прироста для получения количества отсутствующих колец [6]. Второй способ расчета был достаточно точным у быстрорастущих лиственных видов небольшого размера.

Вторая неопределенность связана со временем, прошедшим от момента освобождения территории от деревьев в результате ЭГП до момента появления и закрепления на ней первых деревьев. Этот временной разрыв увеличивается при неблагоприятных климатических, почвенных факторах, несеменных годах и других условиях [33]. Величину разрыва не оценивали, но по возрасту деревьев судили о минимальном возрасте события.

В целом, точность датирования реакций у отдельных деревьев на основе маркеров травматической индикации обычно составляет 1-2 года, дендрометрической - 1 год, анатомической - месяц, сезон (но возможно запаздывание реакции дерева на явление), деформационной - от 1 до нескольких лет, возрастной - приблизительная (от 1 до 100 лет). Основными маркерами для датирования лавин, селей и обвалов/камнепадов являются маркеры травматической и дендрометрической индикации, дополнительными - возрастной и деформационной. Маркеры анатомической индикации зарекомендовали себя в условиях муссонного климата.

Оценка интенсивности отклика. Степень отклика отдельных деревьев на склоновое явление изменяется по интенсивности, в пространстве и во времени и зависит от типа ЭГП, биологического вида и возраста дерева, стратегии отбора образцов и даже характера выявленных нарушений дерева $[9,30,32]$. В последнее время применяются два подхода к оценке интенсивности отклика дерева. При первом подходе для каждого маркера вводились 3-4 категории по интенсивности отклика дерева (от слабого до сильного) по качественным и количественным критериям. Затем вычислялась интенсивность склонового явления по формулам с присвоением своего веса для каждой категории [14, 16, 30, 34]. При втором подходе интенсивность отклика дерева определялась качественно сразу по нескольким маркерам. Затем оценивалась интенсивность склонового явления либо по формулам, либо экспертно [9, 10, 19, 30].

Пороговые величины значений, используемые для разграничения категорий интенсивности отклика дерева и интенсивности склонового явления, получались эмпирическим путем при тематических исследованиях отдельных участков склонов и затем были обобщены [4, 9, 13, 14, 30, 34].

Датирование склонового явления считалось более надежным, если оно подтверждалось (1) разными дендроиндикационными маркерами и (2) на нескольких деревьях [16, 30]. Для повышения надежности реконструкций склоновых явле- ний разработан четырехшаговый алгоритм, который позволил отделить лавинные нарушения от нарушений, вызванных климатическими или иными экзогенными факторами [13].

\section{V. Пространственно-временная реконструкция} включает в себя оценку протяженности, временной вероятности склоновых явлений, реже интенсивности ЭГП. Качество реконструкции зависит от количества, пространственного распределения и возраста отдельных деревьев, а также стратегии отбора древесных образцов и вида дерева [31]. Пространственно-временные характеристики склоновых явлений восстанавливали количественными и полуколичественными методами.

Пространственная протяженность ЭГП восстанавливалась по распределению затронутых тем или иным событием деревьев на местности. На спутниковых изображениях отмечались либо деревья с откликами разной интенсивности в соответствующем году [14], либо деревья с разным возрастом, произрастающие на залесенных конуcax [11]. В последние годы при пространственной реконструкции событий стало применяться цифровое моделирование [18].

Результаты датирования явлений приводились в виде таблиц/диаграмм абсолютного или относительного количества деревьев с нарушениями роста по годам [7, 10, 14, 16, 17, 25, 31, 34]. На их основе рассчитывались частоты этих событий по десятилетиям (frequency) или периоды повторного схода селей/лавин (return period), представляемые в виде (1) таблиц/диаграмм [7, 10] или (2) карт с учетом расположения деревьев с травмами $[10,31,32]$ или с использованием цифровой модели абсолютной высоты и местоположения деревьев, нарушенных при каждом реконструированном явлении [18].

Интенсивность склонового явления оценивалась либо по формулам [11, 14], либо на основе пространственного анализа [7, 12]. В первом случае учитывалось количество нарушенных деревьев и интенсивность их индивидуальной реакции. Остается дискуссионным вопрос о пороговой величине отреагировавших на воздействие деревьев $[8,9,11]$. Во втором случае анализировалось пространственное распределение деревьев с разными видами нарушений. Отмечалось [14], что датирование явлений не всегда возможно, особенно если они сгруппированы во времени или имеют ограниченное распространение на конусе.

\section{ЗАКЛЮЧЕНИЕ}

В кратком обзоре литературы рассмотрены дендроиндикационные методы выявления, датирования и реконструкции селей, лавин, обвалов/камнепадов. Набор этих методов и эффективность их использования варьировали в каж- 
дом конкретном горном районе в зависимости от преобладающего типа ЭГП, биологического вида и распределения древесных растений в пространстве, других особенностей территории и климата. Для оценки этих процессов основными являлась травматическая и дендрометрическая индикации, дополнительными - возрастная и деформационная. Анатомическая индикация требует проверки в условиях континентального климата. Временная глубина дендроиндикационных исследований в прошлое - несколько десятков/сотен лет. Увеличить эту глубину можно в случае использования годичных колец полуископаемой древесины. Индикаторами служили деревья чаще хвойных видов, а основными маркерами их реакций - изменения в структуре и размерах годичных колец, а также возраст деревьев. Такие исследования выполнялись преимущественно в горных районах северного полушария.

Описанные методы фиксации склоновых явлений имеют свои ограничения, которые влияют на полноту реконструированной временной хронологии склоновых явлений и выявление их пространственного распределения на конкретном участке местности. Пространственные реконструкции ограничены наличием деревьев и их распределением на территории, временные - их возрастом, а также точностью датирования.

При датировании ЭГП дендроиндикационными методами до сих пор проблемными остаются следующие методические вопросы: (1) минимальный размер выборки нарушенных деревьев, необходимый для оценки склоновых явлений; (2) выделение из длительных рядов радиального прироста геоморфологического сигнала при датировании ЭГП; (3) неопределенности в оценке абсолютного возраста деревьев и времени заселения территории; (4) применимость методов, разработанных для датирования оползней, к лавинам; (5) количественные критерии оценки интенсивности отклика дерева на склоновое явление с помощью маркеров; (6) качественные и количественные критерии оценки интенсивности склонового явления и минимальная пороговая величина отреагировавших на него деревьев; (7) неполнота датирования крупных склоновых явлений дендроиндикационными методами.

Перспективы дальнейших исследований связаны не только с решением вышеперечисленных вопросов, но и с актуализацией дендроиндикационных исследований в России на новом методическом уровне.

\section{ФИНАНСИРОВАНИЕ}

Исследование было выполнено в рамках госбюджетной темы № АААА-А17-117013050039-4.

\section{БЛАГОДАРНОСТИ}

Авторы благодарят двух анонимных рецензентов за тщательный анализ рукописи и ценные замечания, которые способствовали значительному улучшению текста статьи.

\section{FUNDING}

The article was carried out within the framework of the state-ordered research theme no. AAAA-A17-117013050039-4.

\section{ACKNOWLEDGMENTS}

Authors are grateful to anonymous reviewers for the article's thorough analysis and valuable comments that have improved it.

\section{СПИСОК ЛИТЕРАТУРЫ}

1. Горчаковский П.Л., Шиятов С.Г. Фитоиндикация условий среды и природных процессов в высокогорьях. М.: Наука, 1985. 209 с.

2. Корженевский В.В., Квитницкая А.А. Фитоиндикация рельефообразования и опыт ее применения // Бюлл. Никит. бот. сада. 2011. № 100. С. 5-28.

3. Лехатинов А.М. К методике изучения активности проявления селей горно-таежных областей // Cелевые потоки: катастрофы, риск, прогноз, защита. Южно-Сахалинск: Сахалин. ф-л Дальневост. геол. ин-та ДВО РАН, 2014. С. 43-47.

4. Николаева С.А., Савчук Д.А., Кузнеиов А.С. Датирование селевой активности в горно-ледником бассейне Актру (Горный Алтай) // Геориск. 2017. № 2. C. 56-63.

5. Шиятов С.Г., Ваганов Е.А., Кирдянов А.В., Круглов В.Б., Мазепа В.С., Наурзбаев М.М., Хантемиров Р.М. Методы дендрохронологии. Ч. 1. Основы дендрохронологии. Сбор и получение древеснокольцевой информации. Красноярск: Изд-во КрасГУ, 2000. 80 с.

6. Bollschweiler M., Stoffel M., Schneuwly D. Dynamics in debris-flow activity on a forested cone - a case study using different dendroecological approaches // Catena. 2008. V. 72. № 1. P. 67-78.

7. Bollschweiler M., Stoffel M. Tree rings and debris flows: recent developments, future directions // Progress in Phys. Geogr. 2010. V. 34. № 5. P. 625-645.

8. Butler D.R., Sawyer C.F. Dendrogeomorphology and high-magnitude snow avalanches: a review and case study // Natural Hazards and Earth System Sciences. 2008. V. 8. P. 303-309.

9. Chiroiu P. Geomorphological studies of slope processes by the analysis of tree-rings // Central European Regional Policy and Human Geography. 2013. V. 3. № 1. P. 93-105.

10. Corona C., Rovéra G., Lopez Saez J., Stoffel M., Perfettini $P$. Spatio-temporal reconstruction of snow avalanche activity using tree rings: Pierres Jean Jeanne avalanche talus, Massif de l'Oisans, France. Catena, 2010. V. 83. № 2-3. P. 107-118.

11. Corona C., Lopez Saez J., Stoffel M., Bonnefoy M., Richard D., Astrade L., Berger F. How much of the real ava- 
lanche activity can be captured with tree rings? An evaluation of classic dendrogeomorphic approaches and comparison with historical archives // Cold Regions Science and Technology. 2012. V. 74-75. P. 31-42.

12. Czajka B., Lajczak A., Kaczka R. The influence of snow avalanches on the timberline in the Babia Cora massif, Western Carpathians // Geographia Polonica. 2015. V. 88. № 2. P. 147-161.

13. Favillier A., Guillet S., Morel P., Corona C., Lopez Saez J., Eckert N., Ballesteros Canovas J., Peiry J.-L., Stoffel M. Disentangling the impacts of exogenous disturbances on forest stands to assess multi-centennial tree-ring reconstructions of avalanche activity in the upper Goms Valley (Canton of Valais, Switzerland) // Quat. Geochronology. 2017. V. 42. P. 89-104.

14. Kogelnig-Mayer B., Stoffel M., Schneuwly-Bollschweiler M., Hübl J., Rudolf-Miklau F. Possibilities and limitation of dendrogeomorphic time-series reconstruction on sites influenced by debris flows and frequent snow avalanche activity // Arctic, Antarctic and Alpine Research. 2011. V. 43. № 4. P. 649-658.

15. Lopez Saez J., Corona C., Stoffel M., Gotteland A., Berger $F$., Liebault $F$. Debris-flow activity in abandoned channels of the Manival torrent reconstructed with $\mathrm{Li}-$ DAR and tree-ring data // Natural Hazards and Earth System Sciences. 2011. V. 11. P. 1247-1257.

16. Malik I., Owczarek P. Dendrochronological records of debris flow and avalanche activity in a mid-mountain forest zone (Eastern Sudetes - Central Europe) // Geochronometria. 2009. V. 34. № 1. P. 57-66.

17. Malik I., Wistuba M. Dendrochronological methods for reconstructing mass movements - an example of landslide activity analysis using tree-ring eccentricity // Geochronometria. 2012. V. 39. № 3. P. 180-196.

18. Mesesan F., Gavrila I., Pop O. Calculating snow-avalanche return period from tree-ring data // Natural Hazards. 2018. V. 94. № 3. P. 1081-1098.

19. Schläppy R., Jomelli V., Grancher D., Stoffel M., Corona C., Brunstein D., Eckert N., Deschatres M. A new tree-ringbased, semi-quantitative approach for the determination of snow avalanche events: use of classification trees for validation // Arctic, Antarctic, and Alpine Research. 2013. V. 45. № 3. P. 383-395.

20. Schläppy R., Jomelli V., Eckert N., Stoffel M., Grancher D., Brunstein D., Corona C., Deschatres M. Can we infer avalanche-climate relations using tree-ring data? Case studies in the French Alps // Reg. Env. Change. 2016. V. 16. № 3. P. 629-642.

21. Schweingruber F.H. Tree rings and environment. Dendroecology. Berne, Stuttgard, Vienna: Paul Haupt Publ., 1996. 609 p.
22. Shroder J.F. Dendrogeomorphology; review and new techniques of tree-ring dating // Progress in Phys. Geogr. 1980. V. 4. № 2. P. 161-188.

23. Solomina O.N. Dendrogeomorphology: research requirements // Dendrochronologia. 2002. V. 20. № 12. P. 233-245.

24. Sorg A., Bugmann H., Bollschweiler M., Stoffel M. Debris-flow activity along a torrent in the Swiss Alps: Minimum frequency of events and implications for forest dynamics // Dendrochronologia. 2010. V. 28. № 4. P. 215-223.

25. Stoffel $M$. A review of studies dealing with tree rings and rockfall activity: the role of dendrogeomorphology in natural hazard research // Natural Hazards. 2006. V. 39. № 1. P. 51-70.

26. Stoffel $M$. Dating past geomorphic processes with tangential rows of traumatic resin ducts // Dendrochronologia. 2008. V. 26. № 1. P. 53-60.

27. Stoffel M., Bollschweiler M. Tree-ring analysis in natural hazards research - an overview // Natural Hazards and Earth System Sciences. 2008. V. 8. P. 187-202.

28. Stoffel M., Bollschweiler M. Tree-ring reconstruction of past debris flows based on a small number of samples possibilities and limitations // Landslides. 2009. V. 6. № 3. P. 225-230.

29. Stoffel M., Bollschweiler M., Widmer S., Sorg A. Spatiotemporal variability in debris-flow activity: a tree-ring study at Geisstriftbach (Swiss Alps) extending back to AD 1736 // Swiss J. Geosciences. 2010. V. 103. № 2. P. 283-292.

30. Stoffel M., Corona $C$. Dendroecological dating of geomorphic disturbance in trees // Tree-ring Research. 2014. V. 70. № 1. P. 3-20.

31. Trappmann D., Corona C., Stoffel M. Rolling stones and tree rings: A state of research on dendrogeomorphic reconstructions of rockfall // Progress in Phys. Geogr. 2013. V. 37. № 5. P. 701-716.

32. Trappmann D., Stoffel M. Counting scars on tree stems to assess rockfall hazards: A low effort approach, but how reliable? // Geomorphology. 2013. V. 180. P. 180186.

33. Tumajer J., Treml $V$. Meta-analysis of dendrochronological dating of mass movements // Geochronometria. 2013. V. 40. № 1. P. 59-76.

34. Tumajer J., Treml $V$. Reconstruction ability of dendrochronology in dating avalanche events in the Giant Mountains, Czech Republic // Dendrochronologia. 2015. V. 34. P. 1-9.

\title{
Methods of Dendroindication of Developing Rapid Geomorphic Processes: An Overview
}

\author{
S. A. Nikolaeva ${ }^{1, \#}$ and D. A. Savchuk ${ }^{1, \# \#}$ \\ ${ }^{1}$ Institute of Monitoring of Climatic and Ecological Systems of the SB RAS, Tomsk, Russia \\ \#e-mail: sanikol1@rambler.ru \\ \#\#-mail:savchuk@imces.ru
}


Since the beginning of the 21st century dendrogeomorphological research are abruptly activated in Western Europe but are appreciable reduced in Russia. In the present foreign literature, the new methods and approaches of dendrogeomorphological research has been developed and discussed. The article goal is an overview of the dendrogeomorphological methods for identifying, dating and reconstructing the geomorphic events (debris flows, avalanches, rockfalls), their advantages and limitations at different stages of a dendrogeomorphological study. The dendrogeomorphological research are based on the J. Shroder's "processevent-response" concept. The disputable questions and unsolved issues of the dendrogeomorphology are considered.

Keywords: dendrogeomorphology, debris flow, snow avalanche, rockfall, tree-ring, injury, radial increment, deposit, Altai Mountains

\section{REFERENCES}

1. Gorchakovskii P.L., Shiyatov S.G. Fitoindikatsiya uslovii sredy $i$ prirodnykh protsessov $v$ vysokogor'yakh [Phytoindication of Environmental Conditions and Nature Processes in Highland Areas]. Moscow: Nauka Publ., 1985. 209 p.

2. Korzhenevskii V.V., Kvitnitskaya A.A. Phytoindication of relief forming and experience of its application. Byull. Nikitskogo Botanicheskogo Sada, 2011, no. 100, pp. 5-28. (In Russ.).

3. Lekhatinov A.M. On the methods of studing the activity of mudflows in mountainous taiga areas. In Selevye potoki: katastrofy, risk, prognoz, zashchita [Debris Flows: Disasters, Risk, Forecast, Protection]. YuzhnoSakhalinsk: Sakhalin. Filial. Dalnevost. Geol. Inst. Akad. Nauk, 2014, pp. 43-47. (In Russ.).

4. Nikolaeva S.A., Savchuk D.A., Kuznetsov A.S. Dating of debris flow activity in the Aktru mountain glacier basin (the Altai Mountains). Georisk, 2017, no. 2, pp. 5663. (In Russ.).

5. Shiyatov S.G., Vaganov E.A., Kirdyanov A.V., Kruglov V.B., Mazepa V.S., Naurzbaev M.M., Khantemirov R.M. Metody dendrokhronologii. Ch.1. Osnovy dendrokhronologii. Sbor i poluchenie drevesno-kol'tsevoi informatsii [Methods of Dendrochronology. Part 1. Basics of dendrochronology. Collection and Determination of Tree Ring Information]. Krasnoyarsk: Krasnoyarsk. Gos. Univ., 2000. 80 p.

6. Bollschweiler M., Stoffel M., Schneuwly D. Dynamics in debris-flow activity on a forested cone - a case study using different dendroecological approaches. Catena, 2008, vol. 72, no. 1, pp. 67-78.

7. Bollschweiler M., Stoffel M. Tree rings and debris flows: recent developments, future directions. Prog. Phys. Geogr., 2010, vol. 34, no. 5, pp. 625-645.

8. Butler D.R., Sawyer C.F. Dendrogeomorphology and high-magnitude snow avalanches: a review and case study. Nat. Hazard. Earth Sys. Sci., 2008, vol. 8, pp. 303-309.

9. Chiroiu P. Geomorphological studies of slope processes by the analysis of tree-rings. Central European Regional Policy and Human Geography, 2013, vol. 3, no. 1, pp. 93-105.

10. Corona C., Rovéra G., Lopez Saez J., Stoffel M., Perfettini P. Spatio-temporal reconstruction of snow avalanche activity using tree rings: Pierres Jean Jeanne avalanche talus, Massif de l'Oisans, France. Catena, 2010, vol. 83, no. 2-3, pp. 107-118.
11. Corona C., Lopez Saez J., Stoffel M., Bonnefoy M., Richard D., Astrade L., Berger F. How much of the real avalanche activity can be captured with tree rings? An evaluation of classic dendrogeomorphic approaches and comparison with historical archives. Cold Reg. Sci. Technol., 2012, vol. 74-75, pp. 31-42.

12. Czajka B., Lajczak A., Kaczka R. The influence of snow avalanches on the timberline in the Babia Cora massif, Western Carpathians. Geogr. Pol., 2015, vol. 88, no. 2, pp. 147-161.

13. Favillier A., Guillet S., Morel P., Corona C., Lopez Saez J., Eckert N., Ballesteros Canovas J., Peiry J.-L., Stoffel M. Disentangling the impacts of exogenous disturbances on forest stands to assess multi-centennial tree-ring reconstructions of avalanche activity in the upper Goms Valley (Canton of Valais, Switzerland). Quat. Geochronol., 2017, vol. 42, pp. 89-104.

14. Kogelnig-Mayer B., Stoffel M., Schneuwly-Bollschweiler M., Hübl J., Rudolf-Miklau F. Possibilities and limitation of dendrogeomorphic time-series reconstruction on sites influenced by debris flows and frequent snow avalanche activity. Arct. Antarct. Alp. Res., 2011, vol. 43, no. 4, pp. 649-658.

15. Lopez Saez J., Corona C., Stoffel M., Gotteland A., Berger F., Liebault F. Debris-flow activity in abandoned channels of the Manival torrent reconstructed with LiDAR and tree-ring data. Nat. Hazard. Earth Sys. Sci., 2011, vol. 11, pp. 1247-1257.

16. Malik I., Owczarek P. Dendrochronological records of debris flow and avalanche activity in a mid-mountain forest zone (Eastern Sudetes - Central Europe). Geochronometria, 2009, vol. 34, no. 1, pp. 57-66.

17. Malik I., Wistuba M. Dendrochronological methods for reconstructing mass movements - an example of landslide activity analysis using tree-ring eccentricity. Geochronometria, 2012, vol. 39, no. 3, pp. 180-196.

18. Mesesan F., Gavrila I., Pop O. Calculating snow-avalanche return period from tree-ring data. Nat. Hazards, 2018, vol. 94, no. 3, pp. 1081-1098.

19. Schläppy R., Jomelli V., Grancher D., Stoffel M., Corona C., Brunstein D., Eckert N., Deschatres M. A new tree-ring-based, semi-quantitative approach for the determination of snow avalanche events: use of classification trees for validation. Arct. Antarct. Alp. Res., 2013, vol. 45 , no. 3 , pp. 383-395.

20. Schläppy R., Jomelli V., Eckert N., Stoffel M., Grancher D., Brunstein D., Corona C., Deschatres M. Can we infer avalanche-climate relations using tree-ring data? 
Case studies in the French Alps. Reg. Environ. Change, 2016, vol. 16, no. 3, pp. 629-642.

21. Schweingruber F.H. Tree Rings and Environment. Dendroecology. Berne, Stuttgard, Vienna: Paul Haupt Publ., 1996. 609 p.

22. Shroder J.F. Dendrogeomorphology; review and new techniques of tree-ring dating. Prog. Phys. Geogr., 1980, vol. 4, no. 2, pp. 161-188.

23. Solomina O.N. Dendrogeomorphology: research requirements. Dendrochronologia, 2002, vol. 20, no. 1-2, pp. 233-245.

24. Sorg A., Bugmann H., Bollschweiler M., Stoffel M. Debris-flow activity along a torrent in the Swiss Alps: Minimum frequency of events and implications for forest dynamics. Dendrochronologia, 2010, vol. 28, no. 4, pp. 215-223.

25. Stoffel M. A review of studies dealing with tree rings and rockfall activity: the role of dendrogeomorphology in natural hazard research. Nat. Hazards, 2006, vol. 39, no. 1 , pp. $51-70$.

26. Stoffel M. Dating past geomorphic processes with tangential rows of traumatic resin ducts. Dendrochronologia, 2008, vol. 26, no. 1, pp. 53-60.

27. Stoffel M., Bollschweiler M. Tree-ring analysis in natural hazards research - an overview. Nat. Hazard. Earth Sys. Sci., 2008, vol. 8, pp. 187-202.
28. Stoffel M., Bollschweiler M. Tree-ring reconstruction of past debris flows based on a small number of samples possibilities and limitations. Landslides, 2009, vol. 6, no. 3, pp. 225-230.

29. Stoffel M., Bollschweiler M., Widmer S., Sorg A. Spatio-temporal variability in debris-flow activity: a treering study at Geisstriftbach (Swiss Alps) extending back to AD 1736. Swiss J. Geosci., 2010, vol. 103, no. 2, pp. 283-292.

30. Stoffel M., Corona C. Dendroecological dating of geomorphic disturbance in trees. Tree-Ring Res., 2014, vol. 70, no. 1, pp. 3-20.

31. Trappmann D., Corona C., Stoffel M. Rolling stones and tree rings: A state of research on dendrogeomorphic reconstructions of rockfall. Prog. Phys. Geogr., 2013, vol. 37, no. 5, pp. 701-716.

32. Trappmann D., Stoffel M. Counting scars on tree stems to assess rockfall hazards: A low effort approach, but how reliable? Geomorphology, 2013, vol. 180, pp. 180-186.

33. Tumajer J., Treml V. Meta-analysis of dendrochronological dating of mass movements. Geochronometria, 2013, vol. 40, no. 1, pp. 59-76.

34. Tumajer J., Treml V. Reconstruction ability of dendrochronology in dating avalanche events in the Giant Mountains, Czech Republic. Dendrochronologia, 2015, vol. 34, pp. 1-9. 